\title{
CUSTOMER AND ORGANISATIONAL VALUE ADDED THROUGH CUSTOMER EXPERIENCE DIFFERENTIATION
}

\author{
Adri Drotskie* \\ University of Johannesburg \\ adrid@uj.ac.za
}

July 2010

\begin{abstract}
Previous research has shown that the customer experience is a strategic differentiator leading to a competitive advantage for organisations. The customer experience is the interaction between customer and the organisation and should lead to value add. It is important though that value is added to the customer as well as to the organisation. The focus of this paper is first on what value is. The second part of the paper focuses on a measurement tool that was developed to measure the value to customer (VTC) and the value of the customer (VOC). The measurement tool is validated through application within a retail banking environment. By measuring the value to and of customers an organisation can determine if optimal value is added. The outcome of the measurement can be used by organisations to understand the customer value offering and the financial implications of value and establishing the relevant balance.
\end{abstract}

\section{Keywords}

Value to customer, value of customer, customer experience, management

* Dr Adri Drotskie is a senior lecturer in the Department of Business Management, Johannesburg University, South Africa. 


\section{INTRODUCTION}

Tangible value can be added to both the customer and the organisation by way of a differentiated customer experience. Value is added to the customer (value to customer) as well as to the organisation through the customer's experience (value of customer), leading to optimal value. It is not an either / or situation where tangible value is either added to the customer's bottom line or to the organisation's bottom line. Both the customer and the organisation benefit from the positive experience that the customer has when interacting with the organisation.

This article is based on the assumption that customer experience is a strategic differentiator in industries that interact with customers directly.

After a thorough literature study, the first part of this article provides definitions and views of value to the customer and the organisation. The second part provides a description of the valueto-customer framework as a research methodology that was developed by a team of experts of whom the researcher was a member. Application of this framework for a scientific calculation of value to the customer is discussed, providing proof that a differentiated customer experience adds tangible value as well.

The article concludes with a discussion about the balance between value to the customer and delivery cost efficiency and its impact.

The framework was applied and tested within a retail banking context. The value of the framework is applicable to all industries that interact with customers.

The purpose of the research conducted and described in this article is to show through research that value is added to customers as well as the organisation (value of customers) through a differentiated customer experience. It implies that customer experience can be a tangible value adding factor within the profitability context of an organisation.

Customer experience is seen by organisations or industries that interact with customers as a strategic differentiator, leading to a competitive advantage. However, customer experience is seen by many organisations as an intangible factor within the business context. To give customers an optimal customer experience can often not be quantified as a tangible value add.

The research problem is to determine if the value added to customers and obtained from customers can be measured and therefore be tangible.

\section{DEFINING VALUE TO THE CUSTOMER AND THE ORGANISATION}

\subsection{Defining value}

The following aspects about value to the customer and the organisation were obtained from the literature study.

\subsubsection{Buying value}

Customers do not buy products and services. They buy value - the total package of product performance, access, experience and cost. Organisations that understand how customers define value across these dimensions consistently achieve long-term profitable growth (Kothari \& 
Lackner, 2006:243).

\subsubsection{Value described}

Value in its broadest sense can be described as "beliefs that are shared by the community and provide guidelines for how they would think, act and feel in a given situation" (Cant, Brink \& Brijball, 2002:28).

\subsubsection{Benefits versus costs}

Buyers' perceptions of value represent a trade-off between the perceived benefits of the service and the perceived sacrifice in terms of cost. Total cost to the customer includes more than the monetary price paid for the service. Other costs include time costs, energy costs and psychic costs reflecting the time and trouble the customer has to expend to acquire the service. Similarly, total customer value extends beyond product value and includes service value, personnel value and image value (Hoffmann, 2001:166).

\subsubsection{Emotions and revenue}

Shaw (2007:4) discovered through ground-breaking research in the UK and the USA that every organisation has a previously undetected "emotional signature" embedded in its customer experience and that it affects value generation. This signature is unique to every organisation and can be one of the underlying reasons for good or poor revenue performance. There is, therefore, an empirical link between evoking certain emotions and increasing or decreasing revenue.

\subsubsection{Meaning of value}

Value in an organisational or marketing context has three distinct meanings, namely price value, customer value and strategic value. Customers who buy products and services receive functional benefits (inherent to the product or service), social benefits (what customers want and that influence their decision making), personal benefits (inherent feelings of goodwill and satisfaction with the product or service), and experiential benefits (from using the product or service) (Cant et al., 2002:29-31).

\subsubsection{Value derived}

The "right" customer will derive value from faster deployment, seamless operations, a focus on core activities, fewer up-front costs, reduced support costs and decreased use of internal resources (Kumar, 2004:62-63). Solution providers create customer value by

- helping customers increase revenue,

- assuming customer risk and responsibility for part of the business, or

- reducing the total consumption cost to the customer.

Although powerful solutions are successful in all three dimensions, most solutions have one of these dimensions as primary motivation. 


\subsubsection{Value defined}

Customer value is created when customers' needs and wants are fulfilled. Customer value can be defined as "the difference between all the benefits derived from a product and all the costs of acquiring those benefits" (Cant et al., 2002:30).

\subsubsection{Strategic value}

Value for an organisation is described as "that which the buyer is prepared to pay for the product or service" (Cant et al., 2002:30). Strategic value is defined as the process of meeting or exceeding the customer's expectations pertaining to product, service and cost (Cant et al., 2002:30).

\subsubsection{Differentiation and value}

An organisation may decide on a differentiation, a focus or a low-cost strategy to create value for its customers. A differentiation strategy would imply providing a product or service that is completely different from any other. Customers would feel that they have bought a unique product, and experience a sense of value. A focus strategy would mean that the organisation serves only a small segment of the population and in this way provides exclusive value to its customers. A low-cost strategy would add value because customers pay less for the product than they expected (Cant et al., 2002:30-31). The most widely recognised understanding of value for customers is in the area of price value.

\subsubsection{Adding value}

Cant et al. (2002:31) state that the concept of adding value for the customer is widely discussed in the literature on customer behaviour but sometimes incorrectly interpreted. The only way to determine whether value has been added to the product or service the customer bought is to measure it. This implies finding out what value the customer expected from the product or service, developing a strategy to deliver this value to the customer, and measuring whether the customer's expectations have been met or exceeded.

\subsubsection{Value proposition}

Payne (1994.29) argues that the value the customer receives from the supplier organisation is the total package of benefits derived from the "core product" and "product surrounds", or the added values that enhance basic features such as service and support. The value the customer attributes to these benefits is in proportion to the perceived ability of the offer to solve whatever customer problem prompted the purchase.

This value may be calculated by utilising the value proposition concept and undertaking a value assessment - importantly, working from a customer perspective. There is acceptance of the need for a trade-off between delivering and extracting customer value.

Incorporating the customer's viewpoint throughout the organisation is the essence of customer value management. The customer value management approach is designed to balance the demand for services and products with an infrastructure that is customer-centric, productive and profitable (Payne, 1994.30). This author says that customer value cannot be reduced to functionality versus price. Customer value is composed of both the functional and emotional benefits customers receive minus the financial and non-financial burdens they bear. 


\section{TYPES OF VALUE}

Shaw (2007:121-122) argues that different types of value, ultimately founded on customer behaviour, produce revenue gains over time. Four types of value are relevant to long-term revenue growth, namely extrapolated value, incremental value, strategic value and social network value.

Customer value is therefore the summation of extrapolated, incremental, strategic and social network value.

\subsection{Value and experience}

Leavy (2004:11-12) comments that the business world seems marked by two paradoxes: consumers seem to have more choices that yield less satisfaction, whereas strategists have more options that yield less value. The experience-focused view of value innovation offers a way out. Individual customers seek not so much product variety as experience variety. It is a view that sees a product more as a value portal than a repository.

Leavy (2004:11-12) believes that the growing "disconnect" between the organisation's view of value and the customer's view of value is the driver of transformation. The emerging perspective has two building blocks, namely "experience environments" (the locus of innovation) and "experience networks" (the locus of competences). The most fundamental source of value according to this new perspective is the personalised experience of the individual customer and the quality of the interaction between the customer and the organisation. According to this new perspective, an experience network is "the infrastructure for effectively co-creating value through personalised experiences".

The "shifting locus of innovation" and the "shifting locus of competences" (Leavy, 2004:12) implicit in the co-creation of value paradigm imply that organisations must think again about how to build strategic capital and differentiate themselves in the new competitive landscape. Strategy will no longer be a game of "knowable rules and finite options". Organisations will have to "rethink the meaning of resources and how access to resources is obtained". Organisations will have to learn how to design an internal social architecture, enabling managers "to personalise the way they want to experience the organisation, with a focus on co-creating value" (Leavy, 2004:12).

The only value an organisation creates is the value that comes from customers - current and future customers. Product quality, price and service all factor into a customer's purchase decision. However, assuming the organisation is on par with its competitors, there must be other factors as well. To maximise the return on customers, the organisation must balance current profit from a customer and the long-term change in a customer's value. Return on a customer is maximised at the point where the customer most trusts the organisation, as this trust leads to loyalty and advocacy (Peppers and Rogers, 2005:26-27).

To conclude this discussion of value, it is important to emphasise the fact that value to the customer and value of the customer need to be focused on simultaneously by organisations, and this will lead to optimal, sustainable value and a competitive advantage. This balance that organisations need to create and sustain at all times is depicted in FIGURE 1. 


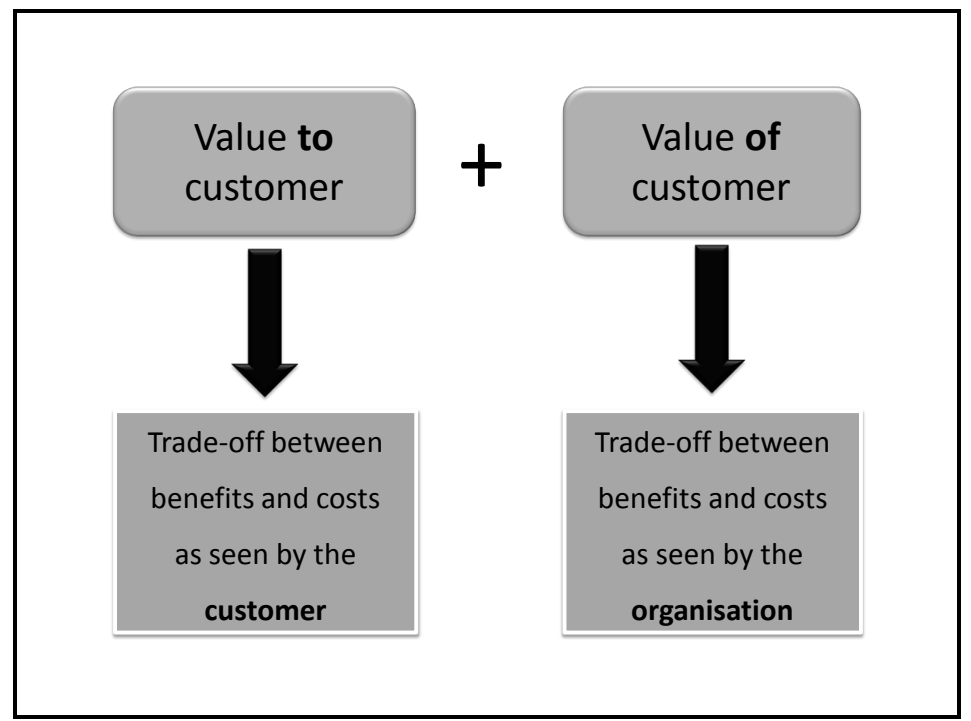

FIGURE 1: Optimal value

Source: Author's analysis

\section{THE VALUE-TO-CUSTOMER FRAMEWORK}

Against the background of value defined and the relation between value and the customer experience, the researcher and a team from a retail banking environment developed a framework to determine the value added to a customer through an experience while interacting with an organisation in relation to the value that is simultaneously added to the bottom line of the organisation. The need in organisations is to understand what monetary value is added to the organisation; therefore the actual value is calculated in rand and cents.

\subsection{Development of the framework}

\subsubsection{Elements of the framework}

The framework that was developed shows the optimal point between the value to customer and the delivery cost efficiency, which represents the value to the organisation or the value of customer. A balance between the two key elements is emphasised (see FIGURE 2). The value of the customer is depicted mainly in the cost efficiency of delivering an experience to the customer through interaction. 


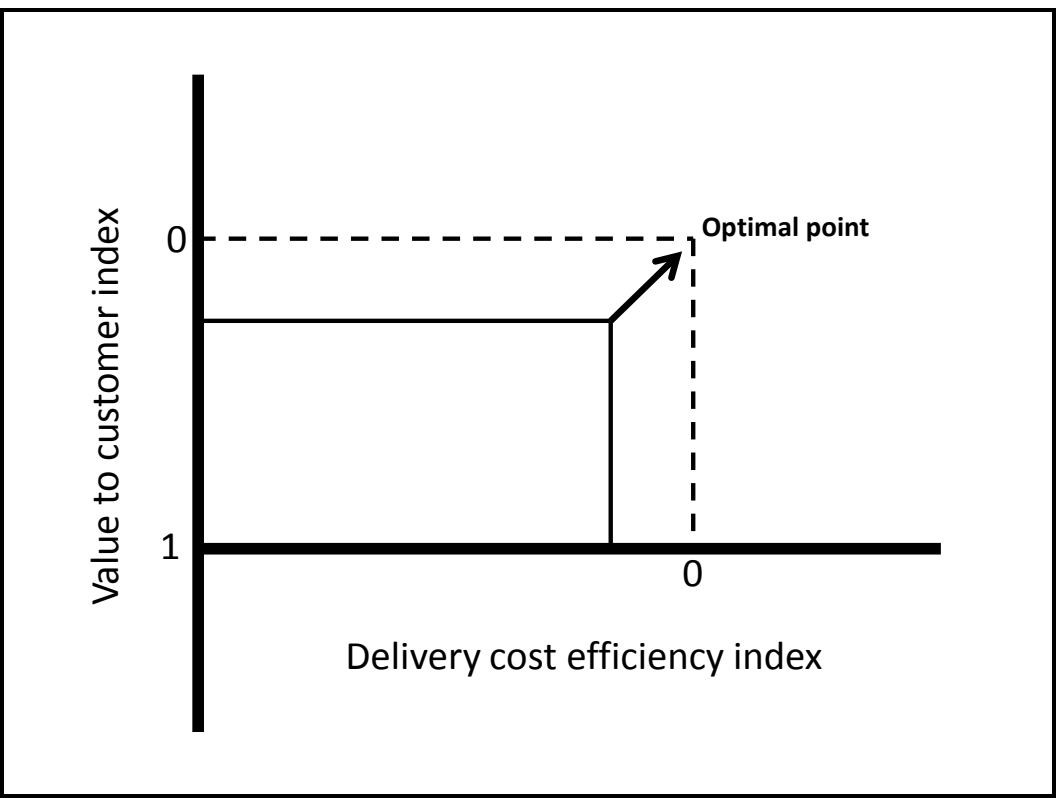

\section{FIGURE 2: The optimal point between customer-centricity and cost efficiency}

\section{Source: Author's analysis}

The optimal point depicted in FIGURE $\mathbf{2}$ is where the optimal value added to the customer equals the optimal delivery cost efficiency in the organisation. The "as is" point is the current value to customer and the current delivery cost efficiency in a given scenario. The difference between the optimal point and the "as is" point is the scope in which the organisation can either add more value to the customer or operate in a more cost-efficient manner without sacrificing the value added to the customer.

\subsubsection{Definitions used in the framework}

The team had to define the newly created concepts and the researcher played an integral role in defining and validating the following definitions:

- Value to customer is defined as "when the brand expectation equals or exceeds the delivery (service/brand) experience".

- Delivery cost efficiency is defined as "the shared services cost-efficiency view in relation to the business revenue generated".

The optimal point between customer-centricity (i.e. value to customer) and cost efficiency (i.e. delivery cost efficiency) is the point where:

I. The organisation utilises all the available resources fully (i.e. from a shared-services perspective - in other words, people, processes, technology and infrastructure)

II. The organisation fully provides value to the customer 


\subsection{Value to customer}

The team that developed the framework looked at all possible elements of the value to customer. The elements of value to customer that include and describe the experience and expectation completely are product, price, delivery and relationship. Value to customer is about the expectations versus the experience the customer had when buying a product, the price the customer had to pay, the interaction through a delivery channel, and the relationship that was formed or maintained.

The following equation contains the formula to calculate value to customer (VTC):

$$
V T C=\frac{\text { Brand expectation }(\text { product }(w)+\text { price }(w)+\text { delivery }(w)+\text { relationship }(w))}{\text { Brand experience }(\text { product }(w)+\text { price }(w)+\text { delivery }(w)+\text { relationship }(w))}
$$

Brand expectation and brand experience are used in the formula, because customer experience equals brand experience, and brand experience is the ultimate experience associated with a specific organisation.

Brand expectation is a historical value that is obtained through questions to customers about their expectations regarding product, price, delivery and relationship. A questionnaire was used to obtain input for the value-to-customer formula. A focus group of customers from a specific segment in the market were asked to complete the questionnaire, which consisted of questions on their expectation regarding product, price, delivery and relationships within a contained area of a specific branch. The value propositions that the organisation developed for this specific segment through the specific delivery channel were also used as an input to understanding customer expectations.

Brand experience is the current value that is obtained through questions to customers about their actual experience regarding product, price, delivery and relationship during a particular interaction. Customers experiencing an interaction with the organisation within the same segment through the same delivery channel, namely a branch, were interviewed to determine their actual experience.

The formula can be applied for an individual customer, a segment of customers, an industry or a total customer base from a product, delivery channel or segment perspective. The uniqueness of the outcome is dependent on the weightings ( $w$ in the formula above) assigned to each element of the formula. The weighting of the elements corresponds to the value proposition for the relevant customer or group of customers (segment).

For example: if the value to customer is determined for the high net worth segment, delivery and relationship will have a much greater weighting than product and price. If the value to customer is determined for the low-income mass market, product and price will have a greater weighting than delivery and relationship. The weightings are determined in accordance with the characteristics and features of the specific grouping that applies to the calculation at the time. The content of the characteristics and features are found in the value proposition or the sales and service strategy of the specific customer or segment.

The value to customer index obtained from the calculation may be plotted as the "as is" point on a graph. The optimal point equals the expectation of the customer. The difference between the "as is" and the optimal points provides an indication of whether the customer received optimal value as expected or whether the organisation is over- or under-delivering. 
The second index applicable to determining the value added to the customer and the organisation is the value of customer. Value of customer is concerned with the value that dealing with a customer adds to the organisation. This value is calculated by means of the delivery cost efficiency. The formula for calculating delivery cost efficiency is depicted in the following equation:

$$
\text { Delivery cost efficiency }=\left(\frac{C 1}{R 1}\right) \times\left(\frac{C 2}{R 2}\right)
$$

$$
\text { where: } \begin{aligned}
& \mathrm{Cl} \\
\mathrm{C} 2 & =\text { Cost year } 1 \\
\mathrm{Rl} & =\text { Revenue year } 1 \\
\mathrm{R} 2 & =\text { Revenue year } 2
\end{aligned}
$$

\section{APPLICATION OF THE FRAMEWORK}

This new breakthrough model had to be tested in a real-time environment to validate its usefulness. The researcher was instrumental in applying the "theory" in an organisation to determine its actual value. The researcher subsequently assumed responsibility for implementation of the model.

The two formulas for value to customer (equation (1)) and delivery cost efficiency (equation (2)) were applied during 2004, using real information from a retail bank in South Africa, named Bank $X$ for the purposes of this article. The delivery cost efficiency was calculated by using information from the financial statements of Bank X for the financial year 2004/05. The purpose of showing these examples is to validate the applicability of the model and not to analyse Bank X's results.

\subsection{Example 1}

A segment of the market was identified from the customer base of Bank X. The customers are all from the middle market and utilised the branch as their main delivery channel for interacting with the organisation.

The delivery cost efficiency ( $D C E$ ) index, as described above, for the specific segment and the specific delivery channel was calculated as 0,141 .

The value to customer (VTC) index, as described in the previous section, for the specific segment and specific delivery channel was calculated as 0,103.

The two indices are placed in relation to each other to determine the optimal point. This is called the optimisation factor, which determines the optimal point depicted in FIGURE 2.

$\begin{array}{lll}\text { The optimisation factor } & =\quad \text { DCE index * VTC index } \\ & =\quad 0,141 * 0,103 \\ & =0,015 \\ \text { Because of a cost inefficiency } & = & 0,015 * C 2\end{array}$




\begin{tabular}{|c|c|c|}
\hline & $=$ & $0,015 * 4291.80$ \\
\hline & $=$ & $\begin{array}{l}\text { R64.38 } \mathrm{m} \text {, derived from the underlying non- } \\
\text { value-adding activities to the customer... }\end{array}$ \\
\hline A revenue potential of & $=$ & $0,015 * R 2$ \\
\hline & $=$ & $0,015 * 11742.10$ \\
\hline & $=$ & $\mathrm{R} 176.13 \mathrm{~m}$ was lost \\
\hline
\end{tabular}

This finding can therefore be utilised by Bank $X$ to understand the value that is currently added to the customers of a specific segment as well as the value that is lost by Bank $X$ due to overdelivery. This information can lead to more efficient utilisation of a delivery channel through understanding the expectations of a customer.

\subsection{Example 2}

A second example comes from the home loans environment in a retail bank where a product was selected to calculate experience versus expectation and cost of delivery in the various delivery channels utilised by a retail bank in delivering a home loan as product to customers, namely the bank branch, developers, mortgage originators and estate agents.

The value to customer index and delivery cost efficiency index were used to calculate the value to and value of customer within the customer base of the home loan product through utilisation of one of the four delivery channels stated above. Based on a weighted average figure (WA), over a period of 18 months from April 2001 - March 2003, the Home Loans business unit of the retail bank could potentially have saved R3.37 million in costs and could potentially have gained R17.96 million in lost revenue. Although these figures are not that significant in the bigger scheme of things within the home loans business unit, these figures tend to escalate exponentially in the third year (based on the analysis of a South African retail bank). It is therefore believed that the greater benefit will become apparent only in the medium term (three to five years) and if the following input refinements are implemented as soon as possible:

- Ensure regular customer satisfaction surveys for whatever review period is chosen (monthly, bi-annually or annually).

- Ensure regular analysis of what specific non-value-adding activities are related to the efficiency or revenue potential figures.

It could also be beneficial to pursue a better understanding of the greater difference in levels of customer satisfaction among developers, mortgage originators and estate agents.

\section{VALUE ADDED THROUGH DIFFERENTIATION}

The two examples stated above were utilised to scientifically prove that the value added to a customer during interaction with an organisation as well as the value added to the organisation during the interaction can be calculated.

It is evident from the calculation of value to customer that if a customer's expectation equals his/her experience or if the experience exceeds the expectation, value is added to the customer. The customer obtains tangible as well as intangible value added. 
The benefits to the organisation are:

- Satisfied customers

- Loyal customers

- Customer retention

Customer retention leads to more selling of products and services, and more transactions and referrals. Customer advocacy comes into play and profitability increases. This is depicted in the service profit value chain in FIGURE 3 below.

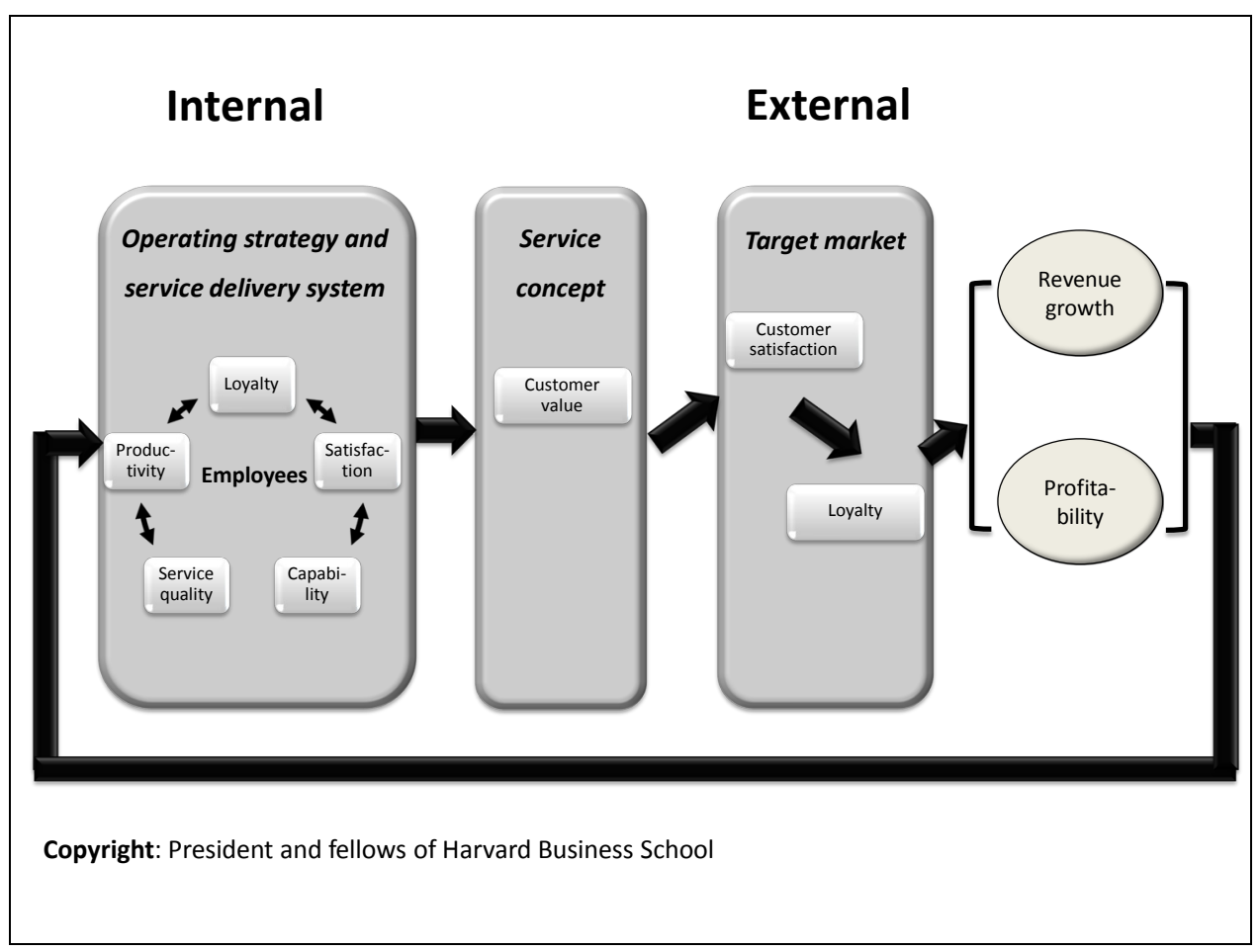

FIGURE 3: Service profit value chain

Source: President and fellows of Harvard Business School

\section{CONCLUSION}

The value that is added to the customer during his or her interaction with the organisation and the value that is added to the organisation through the delivery of the interaction can be calculated. This leads to valuable information that organisations can use to deliver products and services in a more cost efficient manner and ensure a customer experience that equals the expectations of the customer.

Therefore, if customer experience is the differentiator in retail banking or any other industry interacting with customers, adding value to the customer and the organisation through customer experience contributes to the profitability of the organisation and not only to its 
image and brand.

Customer experience as a differentiator is therefore a tangible factor in the profitability framework of the organisation.

\section{REFERENCES}

Cant, M.C., Brink, A. \& Brijball, S. (2002). Customer behaviour - a Southern African perspective. Cape Town: Juta (Pty) Ltd.

Hoffman, K.D. \& Bateson, J.E.G. (2001). Essentials of services marketing: concepts, strategies and cases. London: Thompson Learning.

Kothari, A. \& Lackner, J. (2006). A value based approach to management. Journal of Business and Industrial Marketing, 21(4), pp. 243-249.

Kumar, N. (2004). Marketing as strategy: understanding the CEO's agenda for driving growth and innovation. Boston: Harvard Business School Publishing.

Leavy, B. (2004). Partnering with the customer. Strategy and Leadership, 32(3), pp. 10-13.

Payne, A. (1994). Relationship marketing - making the customer count. Managing Service Quality, 4(6), pp. 29-31.

Peppers, D. \& Rogers, M. (2005). Does loyalty really connect to customer value? Niels SteenfeldtKristensen. Available from: K: KKnowledge Base LLoyalty and CRM\does Loyalty Really Connect to Customer Value.doc. (Accessed 29 November 2005)

Shaw, C. (2007). The DNA of customer experience: how emotions drive value. New York: Palgrave MacMillan.

Thompson, B. (2005). The loyalty connection: secrets to customer retention and increased profits. Right Now Technologies, pp. 1-16. 